\title{
A EDUCAÇÃO INTEGRAL A PARTIR DO OLHAR DE PROFESSORAS DE UMA ESCOLA PÚBLICA
}

\author{
Angela Ariane de Oliveira Santos ${ }^{1}$, Renata Portela Rinaldi ${ }^{2}$ \\ 1 Graduada em Pedagogia pela Universidade Estadual Paulista - UNESP/ Presidente Prudente, SP. E-mail: angelaaos57@gmail.com Agência de \\ fomento: PIBIC/CNPQ. \\ 2 Doutora em Educação pela Universidade Federal de São Carlos - UFSCAR. Professora do Departamento de Educação e do Programa de Pós- \\ Graduação em Educação da Universidade Estadual Paulista - UNESP/ Presidente Prudente, SP.
}

\section{RESUMO}

O artigo apresenta resultados de uma pesquisa de iniciação cientifica, concluída em 2017, que proporcionou reflexão acerca do tempo e do espaço da escola pública de tempo integral. Nesta produção, tivemos como objetivo analisar as concepções de três professoras em exercício em uma escola pública que implantou a educação integral desde 2010, bem como desafios apresentados por elas, a partir das proposições legais de ampliação do tempo diário na escola. Trabalhou-se com pesquisa bibliográfica e com o trabalho de campo, sendo utilizado para coleta de dados desse último o questionário e entrevista; os resultados foram analisados a partir de uma perspectiva descritivo-analítica. Os resultados revelaram que as pesquisas recentes são escassas sobre o tema e desenvolvidas com foco no ensino fundamental. Quanto as concepções das professoras, estão atreladas a ampliação da jornada de permanência da criança na escola, sem articulação curricular, possibilita aplicar atividades complementando/reforçando o aprendido no turno regular.

Palavras- chave: Educação Integral, Concepções de Professoras, Escola Pública.

\section{INTEGRAL EDUCATION FROM THE PERSPECTIVE OF TEACHERS IN A PUBLIC SCHOOL}

\begin{abstract}
The article presents the results of a scientific initiation research concluded in 2017, that provided reflection on the time and space of the full - time public school. In this production, we aimed to analyze the conceptions of three regular teachers in a public school that has implemented integral education since 2010, as well as the challenges presented by them, based on the legal proposal to increase daily time in school. We made use of the bibliographical research and the field work, being the questionnaire and interview used to collect data of the latter; the results were analyzed from a descriptive-analytical perspective. The results revealed that recent research is scarce on the subject and developed with a focus on elementary education. Regarding the conceptions of the teachers, they are linked to the extension of child's stay in school, without curricular articulation, making it possible to give activities that complement/ reinforce what was learned during the regular shift.
\end{abstract}

Keywords: Integral education. Teacher conception. Public school.

\section{INTRODUÇÃO}

Diversos autores apontam que as primeiras discussões sobre Educação Integral, em âmbito nacional, surgiram na década de vinte do século passado e ganharam força perante a proposta de reforma pedagógica dos Pioneiros da Educação Nova. Sabe-se que no ano de 1932 intelectuais redigiram o Manifesto dos Pioneiros, com o intuito de implementar um Sistema de Ensino Público, unificando leitura, escrita, artes, educação, saúde, alimentação e etc.
Vislumbraram uma escola "viva", pública, laica, obrigatória e gratuita que viria a sofrer alterações perante o meio social. Dentre os estudiosos que assinaram o Manifesto dos Pioneiros da Educação, podemos destacar Anísio Teixeira que no de 1950 obteve uma experiência bemsucedida de educação integral em Salvador com o Centro Educacional Carneiro Ribeiro (CECR). Este centro integrava as Escolas-Classe e EscolasParque, que ofereciam uma educação integral incluindo visão de mundo, discussões civis, 
alimentação, atividade esportiva e artísticas, socializantes e de preparação para o trabalho, entre outras práticas. Durante o Regime Militar o centro foi fechado, sendo reinaugurado apenas em 2002 e se enquadrando numa escola com currículo diversificado.

$\mathrm{Na}$ década de 1980, Darcy Ribeiro concebe os Centros Integrados de Educação Pública (CIEPS) um plano de oferecer ensino público em período integral no Rio de Janeiro, inspirado nos êxitos de Salvador. A instituição idealizada era voltada para as crianças das classes populares, o objetivo era proporcionar educação, esportes, assistência médica, alimentos e atividades culturais variadas.

Passados alguns anos a Constituição Federal (BRASIL, 1988) abarca três artigos que fazem referência à educação integral, mesmo não descrevendo explicitamente o conceito no texto. O artigo 205 da Carta Magna assegura:

A educação, direito de todos $e$ dever do Estado e da família, será promovida e incentivada com a colaboração da sociedade, visando ao pleno desenvolvimento da pessoa, seu preparo para o exercício da cidadania e sua qualificação para o trabalho. (BRASIL, 1988, art. 205).

Por sua vez, o Estatuto da Criança e do Adolescente (ECA), Lei n.o 9089/1990, reforça a educação integral como meio para promoção do desenvolvimento da criança e do adolescente.

Os municípios, com apoio dos estados e da União, estimularão e facilitarão a destinação de recursos e espaços para programações culturais, esportivas e de lazer voltadas para a infância e a juventude (BRASIL, 1990, art. 59).

Em 1996 a Lei de Diretrizes e Bases da Educação Brasileira (LDB) foi aprovada. Seu artigo 34a trata da jornada escolar do ensino fundamental que "[...] incluirá, pelo menos, quatro horas de trabalho efetivo em sala de aula, sendo progressivamente ampliado o período de

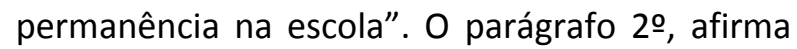
que: "O ensino fundamental será ministrado progressivamente em tempo integral, a critério dos sistemas de ensino", e "[...] serão conjugados todos os esforços objetivando a progressão das redes escolares públicas urbanas de ensino fundamental para o regime de escolas de tempo integral" (BRASIL, 1996, art. 87, § 50).

$\mathrm{Na}$ atualidade, contudo, o grande salto no âmbito da educação integral originou do Programa Mais Educação criado pela Portaria Interministerial no $17 / 2007$, que está imbricado ao Plano de Desenvolvimento em Educação com objetivos de ampliação da jornada escolar e reorganização curricular junto a processos pedagógicos de diversas áreas/macrocampos (meio ambiente, cultura, artes, saúde, esporte, cultura digital e etc.).

No bojo desta mudança, a Resolução do Conselho Nacional de Educação (CNE) de 2010, fixa Diretrizes Curriculares Nacionais para o Ensino Fundamental de 9 (nove) anos. Em seu art. 360 expõe que "[...] é considerado período integral toda jornada escolar organizada em sete horas diárias, resultando em carga horária anual de 1.400 horas". 0 artigo $37^{\circ}$ orienta que além da ampliação do tempo, o ensino tem como objetivo criar novos espaços e oportunidades, fomentando maior envolvimento de outros profissionais da escola, dos familiares e demais setores sociais. $\mathrm{O}$ primeiro inciso deste artigo menciona:

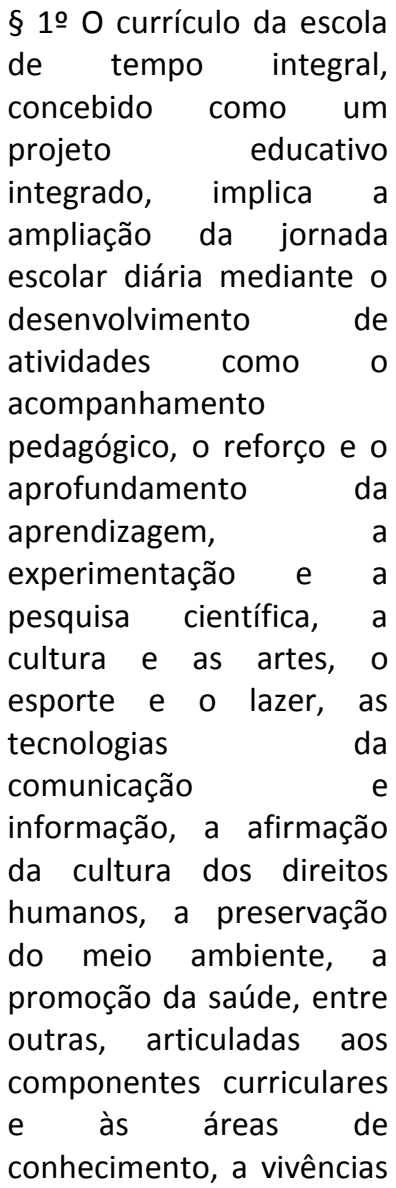


e práticas

socioculturais.(BRASIL,

2010, p. 11)

Segundo dados do Centro de Referências em Educação Integral, em 2015, o Mais Educação alcançava quase 60 mil escolas nos 26 estados e Distrito Federal. Reformulado pelo atual governo, o programa, a partir de 2017, focará em atividades de acompanhamento escolar e diminuirá seu alcance para cerca de 25 mil escolas, ou seja, um decréscimo aproximadamente $42 \%$ de instituições atendidas. Nesse sentido, é importante retomar os apontamentos de Amorim (2013) quando enfatiza:

O projeto de educação integral [...] não poderá se resumir a uma ação estratégica de indução apenas de um dado governo, mas na busca por um compromisso social e político da sociedade, para tanto será importante que esteja articulado com os princípios e finalidades da escola (AMORIM, 2013, p. 6)

A autora vai além, afirma que a política de educação integral:

[...] pressupõe um constante investimento na formação inicial e continuada de professores e demais profissionais da educação. Uma política consistente de valorização profissional, garantida pelos gestores públicos, de modo a permitir dedicação exclusiva e qualificada à educação. Neste sentido, a educação integral em tempo integral pode passar a ser compreendida não apenas em relação aos estudantes da educação básica, mas também aos professores: "A escola de tempo integral exige professor de tempo integral. $\mathrm{O}$ professor que ministra aulas em um turno precisa acompanhar ou, ao menos, orientar as atividades realizadas no outro. Com isso o professor terá dedicação exclusiva na escola" (GIOLO, 2012, p.102, apud AMORIM, 2013, p.6).

Diante do exposto, no presente texto, que deriva de uma pesquisa de iniciação científica (SANTOS; RINALDI, 2016), nos detivemos a identificar e analisar as concepções e os desafios enfrentados pelas professoras de uma escola de tempo integral no município de Presidente Prudente.

\section{METODOLOGIA}

A pesquisa pautou-se em uma abordagem qualitativa, portanto caracterizou-se como um "[...] processo formal e sistemático de desenvolvimento do método científico" (GIL, 2008 , p. 26). Este mesmo autor defende que a pesquisa deriva de ordem intelectual, com a finalidade de conhecer algo e então agir. Nesse sentido, com a finalidade de atingir os objetivos da pesquisa, o estudo configurou-se como sendo de natureza qualitativa, pois investigou a escola e seus envolvidos compreendendo um

[...] universo de
significados, motivos,
aspirações, crenças,
valores e atitudes, o que
corresponde a um espaço
mais profundo das
relações, dos processos e
dos fenômenos que não
podem ser reduzidos à
operacionalização de
variáveis (MINAYO et. al.
2002, p. 22)

É marcante na investigação, ora finalizada, a pesquisa bibliográfica. E de acordo com Gil (2008, p. 50)

A pesquisa bibliográfica é desenvolvida a partir de material já elaborado, constituído principalmente de livros e artigos científicos. Embora em quase todos os estudos seja exigido algum tipo de trabalho desta natureza, há pesquisas desenvolvidas exclusivamente a partir de fontes bibliográficas [...] A principal vantagem da 


\begin{abstract}
pesquisa bibliográfica reside no fato de permitir ao investigador a cobertura de uma gama de fenômenos muito mais ampla do que aquela que poderia pesquisar diretamente. Esta vantagem se toma particularmente importante quando o problema de pesquisa requer dados muito dispersos pelo espaço.
\end{abstract}

Em particular, a pesquisa bibliográfica ocorreu predominantemente via Internet, na seleção de artigos completos da base de dados das Reuniões Nacionais da Associação Nacional de Pós-Graduação e Pesquisa em Educação (ANPEd). De acordo com Severino (2007, p. 140) "[...] como se trata de uma enorme rede, com um excessivo volume de informações, sobre todos os domínios e assuntos, é preciso saber garimpar, sobretudo dirigindo-se a endereços certos". Portanto, a busca se firmou numa base de dados confiável, que fomenta pesquisas em educação, realizadas por professores e estudantes vinculados a pós-graduação. Mapeamos artigos completos tendo em vista as temáticas: Formação Continuada, Formação Inicial e Escola em tempo Integral, realizando primeiramente uma leitura dos resumos de todos os artigos que compunham os seis Grupos de Trabalhos (GT), a saber: GT4 Didática, GT8 Formação de Professores, GT10 Alfabetização, leitura e escrita, GT12 Currículo, GT13 Educação Fundamental e GT16 Educação e Comunicação. Caso o resumo correspondesse ao conjunto de temas investigado ou explanasse direta ou indiretamente resultados sobre ampliação da jornada escolar, educação integral, formação inicial e contínua de professores, este era selecionado para a leitura na íntegra.

A pesquisa envolveu também o trabalho de campo ${ }^{1}$, desenvolvido em uma escola da rede municipal de ensino de Presidente Prudente que foi selecionada a partir dos seguintes critérios: fazer parte do Programa de Educação Integral intitulado Programa Cidadescola e firmar parceria com a universidade. Como participantes, foram convidadas três professoras que trabalham ou trabalharam no Programa Cidadescola e também quatro membros da equipe gestora, comportando diretora, vice-diretora, professora articuladora e orientadora pedagógica. Entretanto, reiteramos, para o presente artigo, que analisaremos apenas as concepções das docentes, ora identificadas como D1, D2 e D3.

A coleta de dados ocorreu por meio do questionário e de entrevista com todas participantes. Após o tratamento dos dados, por meio de transcrição e tabulação das informações, a análise ocorreu numa perspectiva descritivoanalítica.

\section{RESULTADOS}

$O$ que revelam os estudos da ANPEd sobre o tema?

O resultado da pesquisa na base de dados da ANPEd pode ser observado no Quadro 1.

\footnotetext{
${ }^{1}$ Protocolo do CEP 10206912.2.0000.5420 
Quadro 1. Total de trabalhos por GT.

\begin{tabular}{|l|c|c|}
\hline \multicolumn{1}{|c|}{ Grupo de Trabalho } & $\begin{array}{c}\text { Total de Trabalhos } \\
\text { Mapeados }\end{array}$ & $\begin{array}{c}\text { Total de trabalhos } \\
\text { selecionados para } \\
\text { análise }\end{array}$ \\
\hline GT4 -Didática & 75 & 13 \\
\hline GT8 - Formação de Professores & 120 & 35 \\
\hline GT10 - Alfabetização, leitura e escrita & 89 & 7 \\
\hline GT12 - Currículo & 107 & 15 \\
\hline GT13 - Educação Fundamental & 92 & 13 \\
\hline GT16 - Educação e Comunicação & 92 & 40 \\
\hline TOTAL & $\mathbf{5 7 5}$ & $\mathbf{1 2 3}$ \\
\hline
\end{tabular}

Fonte: Sistematizado pelas autoras a partir da base de dados do Portal da ANPED.

Nota-se que o número de trabalhos mapeados foi expressivo, totalizando 575; contudo, numa primeira análise somente $21,3 \%$ dos artigos foram selecionados para a pesquisa. Os demais foram descartados, pois não atendiam aos critérios previamente definidos.

Do total de textos analisados inicialmente, apenas 10 vinculavam-se diretamente ao objeto de estudo, portanto foram analisados na íntegra. O que nos chamou a atenção foi que a grande maioria dos textos foi publicada no GT13 com regularidade ao longo dos anos (Quadro 2) e a hipótese formulada para esse achado é que a proposta de Escola em Tempo Integral destina-se a esta faixa etária.

Quadro 2. Distribuição de trabalhos analisados por Grupo de Trabalho.

Fonte: Sistematizado pelas autoras

\begin{tabular}{|c|c|c|}
\hline ANO & GRUPO DE TRABALHO & QUANTIDADE \\
\hline 2010 & GT 13- Educação Fundamental & 01 \\
\hline \multirow[t]{2}{*}{2011} & GT 12- Currículo & 01 \\
\hline & GT 13- Educação Fundamental & 02 \\
\hline 2012 & GT 13- Educação Fundamental & 01 \\
\hline \multirow[t]{2}{*}{2013} & GT 08- Formação de Professores & 01 \\
\hline & GT 13- Educação Fundamental & 02 \\
\hline 2015 & GT 13- Educação Fundamental & 02 \\
\hline
\end{tabular}

\section{As professoras que atuam no Programa} Cidadescola na Escola e seu olhar sobre o tema

A partir dos resultados coletados por meio do trabalho de campo foi possível delinear o perfil das professoras que participaram do estudo. São profissionais na faixa etária de 40 anos de idade, todas com o vínculo empregatício efetivo na unidade escolar. O tempo, de atuação na escola varia entre 6 e 14 anos, sempre lecionando no 3 ㅇ e 50 ano no turno regular.

A D1 atua no Programa Cidadescola desde a sua implantação na escola em 2010; atualmente mediando oficinas de orientação de estudo e leitura e matemática. Por sua vez, D2 atua há quatro anos no programa oferecendo a oficina de orientação de estudo e leitura; e D3 atuou apenas em 2016 no laboratório de informática, atualmente sem função, informando que o motivo da não continuidade no programa foi a não renovação das licenças de softwares expirados.

O trabalho de codificação e análise dos dados revelou, inicialmente, duas concepções de educação integral: uma compreendida como mera complementação do turno regular e a outra mais voltada para a formação do sujeito, como se observa no Quadro 3: 
Quadro 3. Concepções das docentes sobre educação integral a partir do questionário.

\begin{tabular}{|c|l|}
\hline Participantes & \multicolumn{1}{c|}{ Respostas } \\
\hline D1 & Complementação da educação realizada no turno regular. \\
\hline D2 & $\begin{array}{l}{[\ldots . .] \text { onde os alunos que realizam o projeto conseguem adquirir }} \\
\text { mais conhecimentos através das atividades realizadas que não } \\
\text { dão tempo de aplicar no turno regular [...] }\end{array}$ \\
\hline D3 & Educação que abrange vários temas e em horário estendido. \\
\hline
\end{tabular}

Fonte: Sistematizado pelas autoras a partir dos dados do questionário

Por sua vez, na entrevista a D1 apresenta implicitamente a seguinte concepção sobre educação integral:

Eu vejo assim [o Programa Cidadescola], que eu acabo trabalhando o que de manhã [turno regular] deixa a desejar, às vezes mais a leitura, a matemática mais com jogos [...] - D1.

Quanto aos desafios, a professora relata que:

[...] ônibus é muito complicado para a gente conseguir, por exemplo, às vezes você quer levar a criança na Biblioteca Municipal [...] porque se a gente nunca levar, nunca eles vão, a maioria, algum pode ir, mas a maioria não vai. [...]. Ter mais disponibilidade de ônibus, mais horário de planejamento, material às vezes a gente pede $\mathrm{e}$ demora para chegar alguma coisa diferente [...] No Novo Mais Educação está colocado que é para vinte [alunos] a oficina de orientação de estudo, mas a gente tem vinte e oito [...] é outra sala - D 1.

Apesar dos desafios com infraestrutura, transporte e excesso de alunos na sala, D1 também aponta avanços 2017 em relação aos anos anteriores:

[...] agora a professora
comunitária está
recebendo mais formação
[...] para trazer para a
gente [...] a sala de dança
também é bem
organizada, a organização

na escola, o ambiente está legal, a biblioteca [...]. D1

Para D2, a concepção de educação integral vai ao encontro do que D1 apresentou:

Seria assim, você no turno regular trabalhar o que você precisa realmente, principalmente agora, esse ano que é Prova Brasil, [o] IDEB tem que subir, então você trabalha conteúdo. E jogos, bingo, essas coisas, o concreto [...]eu trago para o turno do Cidadescola - D2.

Quanto aos desafios, aponta:

[...] Nós não temos hora [para planejar], nós temos uma hora [na semana], apenas! $O$ que significa isso? O que você faz em uma hora? Praticamente nada. [...] Antes nós recebíamos por 75 horas, hoje é por 50 horas - D2.

Da mesma forma, apesar dos problemas, a professora acredita que avanços estão por vir:

Teve uma formação, agora, há uns quinze dias, uma formação de português e matemática, mas muito rápida [...] a gestão administrativa já foi tirando muitas coisas sem um diálogo, sem uma conversa com os outros, então acredito que depois do recesso, quando a gente voltar virá com novas coisas, novas informações, novos intuitos, para a gente ter algo melhor - D2. 
Para D3, sua concepção de educação integral está amparada em suas práticas e explica:

O integral é para a criança desenvolver as suas capacidades, ir além do regular, da sala de aula, das disciplinas [...] Quando eu trabalhava com a informática [...] eles tinham a oportunidade de ler e depois retirar as informações das cruzadinhas, caçapalavras. Na sala regular a criança tem livro, caderno, lousa [...] quando ela vem para o outro horário precisa ter um diferencial porque senão não consegue, fica cansada [...]- D3.

No que tange aos desafios a professora aponta:

Precisava de um pouco mais de manutenção no laboratório [de informática] [...] algumas vezes coloquei três alunos em um único computador, o técnico vem somente quando chama [...] no começo também as crianças achavam que aula no laboratório era ficar brincando, mas depois eles entenderam [...] a gente precisa de mais apoio humano e melhor remuneração [...]Docente 3.

Apesar das dificuldades, a professora também indica avanços que observou ao longo do tempo, por exemplo "[...] quando você vê que a criança não está mais com dificuldade [...], nós temos a vantagem de ter salas preparadas, ter os materiais, a gestão investe muito, tem espaço, houve adaptações [...]"

\section{DISCUSSÃO}

Os resultados apresentados revelaram que as concepções de educação integral apresentadas pelas docentes estão atreladas a ampliação da jornada de permanência da criança na escola, que possibilita aplicar atividades complementando/reforçando o aprendido no turno regular. Entretanto, percebe-se uma concepção de currículo ainda fragmentada e binária e sem articulação, especialmente em ano de avaliação externa e em larga escala.

A esse respeito, retomamos Macedo (2002, p. 12) que "[...] ressalta a importância do desenvolvimento de um conjunto de habilidades sobre três pares fundamentais para uma vida cotidiana escolar bem-sucedida: espaço, objetos e tarefas, bem como nós mesmos e as outras pessoas". Desses pares apontados pelo autor, identificamos os desafios relatados pelas professoras, ou seja, espaço precário com infraestrutura comprometida para o desenvolvimento de um trabalho com as crianças, bem como do tempo necessário ao professor para planejamento de sua ação; objetos que deixam de funcionar e não têm assistência; tarefas que devem se voltar ao reforço escolar para melhorar o desempenho dos estudantes, consequentemente, os índices de avaliação a que as escolas estão submetidas. No entanto, são unânimes as professoras ao afirmar que avanços podem ocorrer com a melhoria da formação profissional.

\section{CONCLUSÃO}

Sabemos que as mudanças, quando ocorrem, são muitas vezes superficiais e assim, sujeitas a serem novamente alteradas, por serem inadequadas ou outros motivos. $\mathrm{O}$ modo como políticas são construídas, promulgadas e chegam às escolas e aos professores também afeta fortemente o envolvimento dos professores e sua implicação na implantação podem vir a ser o desgaste profissional e $o$ estresse. Os professores, de modo geral, não participam da elaboração das políticas que precisam implementar, não têm acesso direto a elas e não têm oportunidade de discutir, com os pares, seus pressupostos, objetivos e meios para sua implementação.

Ora, os professores precisam antes se apropriar e depois testar as mudanças, pois estas afetam tanto seu conhecimento como sua prática junto aos seus alunos e por isso, muito prudentemente, nunca mudam radicalmente seu modo de ver, pensar e agir. Vão mudando aos poucos, de acordo com os resultados que vão percebendo nas aprendizagens dos alunos, pois é isso, na verdade, que norteia o trabalho docente cotidiano. 


\section{REFERÊNCIAS}

AMORIM, Joseane Maria de Aguiar. Docência e educação integral: percepções das professoras da escola básica Adotiva Liberato Valentim. 2013. Disponível em:

https://repositorio.ufsc.br/bitstream/handle/123 456789/105647/Joseane\%20Maria\%20de\%20Agu iar\%20Amorim.pdf? sequence $=1$. Acesso em: 12 dez. 2016.

BRASIL. Estatuto da criança e do adolescente. Lei federal no 8.069, 1990.

BRASIL. Lei no 9.394, de 20 de dezembro de 1996.

BRASIL. Texto referência para o debate nacional. Série Mais Educação, 2009.

BRASIL. Resolução CNE/CEB no 07 de 14 de Dezembro de 2010.

GIL, Antonio Carlos. Métodos e técnicas de pesquisa social. 6. ed. São Paulo: Atlas, 2008.

MACEDO, Lino de. Reflexões sobre o cotidiano na sala de aula. Pátio Revista Pedagógica, Porto Alegre, v. 6, n. 22, 2002.

MINAYO, Maria Cecília de Souza et. al. Pesquisa social: teoria, método e criatividade. 21. ed. Petrópolis, RJ: Vozes, 2002.

SEVERINO, Antônio Joaquim. Metodologia do trabalho científico. 23.ed. rev. e atual. São Paulo: Cortez, 2007.

Recebido para publicação em: 16/08/2017

Revisado em: 20/09/2017

Aceito em:02/10/2017 